\title{
Getting more than was Registered for: Reciprocal Benefits from Post-Graduate Faculty E-Mentoring
}

\author{
${ }^{1}$ Thomas Hughes, ${ }^{2}$ Jennifer Mouw \\ ${ }^{1}$ Northern Arizona University \\ ${ }^{2}$ Oak Harbor School District
}

\begin{abstract}
This paper provides a conceptual overview, coupled with insights drawn from a case-study vantage point. It represents a combined higher education and $K-12$ research effort ultimately pointing to benefits from extended electronic contact and collaboration beyond graduation. It represents an important attempt to further support new administrators at a point in time when the role of educational leader is only growing in complexity and training programs are struggling to adjust to new accountability requirements and delivery options of their own. This paper is based upon the current and emerging realities within the United States, and advances options that could effectively augment current efforts to support novice leadership at building and higher organizational levels.
\end{abstract}

\section{Introduction}

All around the world, education is experiencing exponential changes in technologies and expectations. Add to this in many settings, certainly including the United States, it is persistently and concomitantly being publicly scrutinized for the perceived mishandling of its own affairs [6]. Educational administrators are facing increasingly diverse challenges from stakeholders representing every corner of society, all while being tasked with preparing students to deal with demands and potential careers that do not even exist yet [11]. It is not an easy time to be an educator. It has never been more challenging to be a leader. Without question, to be starting out in educational leadership at this point in time is an incredibly challenging endeavor.

A variety of remedies have been advanced to counter the many affronts being felt by schools. The favored strategies depend on perceived need, prevailing philosophies, and currently available opportunities in each setting. In the United States, following a business strategy has long been in vogue, and considered the clear way to "fix" schools. Consequently, the utilization of large corporation type strategies and planning techniques, perhaps even along the lines of transformative scenario planning [7] meets with approval from some. A vastly more familiar path to preparing for future problems is standard strategic planning as described and advocated by Bryson [3] and others. Though there are different names and variations in approach, much of the focus of business strategy tends to be about creating winning structures to identify and overcome organizational challenges.

In contrast to the "business beats all" style, there are those more in tune with an alternate path to improving education, including Petersen [12], that look toward more of a "people oriented" solution to overcoming long-term issues. In keeping with an approach advocated by Hughes [6] that emphasizes people as the critical difference maker, there is growing support for ongoing post-graduate professional development [14] that is more in tune with unique adult learner needs, and addresses "in field" demands and challenges as they present themselves. While the growing value placed on high quality postgraduation professional development is warranted, it is not always going to be timely enough for novice administrators. That gap cannot possibly be entirely unseen, yet it persists and makes one wonder how it could ever be acceptable to "eventually" respond to administrator needs? More timely support must be provided to new leaders who address important challenges on a daily basis.

The concepts being forwarded in this article consider a wide variety of strategies, including the popular structural functional fixes that are widely believed to replicate American business success. That said, in looking at the complexity of daily challenges faced by school administrators, the authors find favor with, and have gravitated more toward a humanistic approach to developing capacity within schools and their leaders. At times, even those aligned with this path end up drifting back into accountability circles. Such was the case when mentoring researchers focused first and foremost on successful compliance with the latest available round of professional standards [13]. For reasons raised, barriers about to be described, as 
well as challenges yet to be detected or defined, an argument for more timely supports for the novice administrator will be presented and discussed throughout this paper.

In the United States, in the eyes of the authors, one of the most troubling challenges faced by today's administrators has to do with the multi-leveled limitations propagated by government-imposed mandates. The strongest criticisms being voiced typically center on yet another "annual" change in direction, affected teaching time, and limited financial resources again being reprioritized by those out of touch with local circumstances. Less obvious to many would be the long-term negative effect mandates appear to have on sustainable leadership efforts. Whereas the curriculums in American graduate leadership programs are still founded upon leadershipcentered ideals, growing external expectations for practitioners back practicing administrators into much more of a compliance orientation [9]. New administrators are extensively schooled on "leadership." Ironically, however, they are increasingly expected to function more like managers instead. Mouw and Hughes discussed how targeted mentoring could help novice leaders not only survive, but actually succeed within such captive circumstances [9].

It is not the purpose of this paper to detour into an inquisition concerning the perceived differences between leadership and management ideals. Rather, the focus of this presentation is intended to begin by considering the unique circumstances and every day challenges surrounding a new school administrator in the United States. This is followed by examination of the changing conditions all American administrators, novice and veteran alike, increasingly find themselves contending with. Contributing to the complexity of addressing these future challenges turns the focus to changes that are now finding their way into higher education corridors. Finally, drawing upon conceptual considerations along with administrator insights, this project advances multiple benefits of mentoring. More specifically it explores lesser considered variations that have also demonstrated success.

\section{Novice Administrator Realities}

As detailed by Augustine-Shaw and Liang [2], the appointment of a novice educational leader presents most schools and also their greater community with a blend of positive energy and a potential dose of occasional uncertainty. New administrators typically start their assignments weeks ahead of students and staff who are returning to start the new year. While the public may ultimately somehow view school breaks as a vacation even for administrators, those times are characteristically bustling with responsibilities. These duties often include hiring new staff, planning for professional development, meeting new people, and a variety of demands that immediately provide the new leader with plenty of first-time challenges. Almost as a rule, no matter where they came from, or where they received their training, real life will require the novice to rapidly transition beyond their highly theoretical initial preparation.

Whether they are familiar with their surroundings or not, it is a given novice administrators will be expected to speak effectively about their vision, and efficiently describe their sense of shared mission. In as much as almost every set of standards ever developed places vision and mission front and center as job number one, possessing a working vocabulary and entry level familiarity concerning educational planning is a fair expectation for those receiving recent training. It is one thing, however, to talk conceptually about culture or climate, and a markedly different challenge to accurately interpret then deliver positive cultural supports in a live setting.

Most sets of approved national standards seem to direct attention to local context and community realities very late in their sequence of directives. Realistically then, the whole concept of developing a vision and mission around authentic local needs, as opposed to showcasing mandates, might not be very clearly developed in the mind of the new administrator. As effectively addressing culture and climate are advanced leadership skills, chances are a novice administrator tasked with engaging their staff would likely require significant immediate assistance. Waiting for professional development sometime in the future just might not be sufficient for meeting this expectation, or many others that will not wait either.

When you think about it, planning is actually a highly-emphasized topic in most training programs. In comparison, how prepared are novice administrators to fill "hard to find" teaching positions by leading high quality hiring practices? Upwards of around $70 \%$ of a school's budget is devoted directly to personnel. Every day, schools commit almost three quarters of their financial resources to a decision effectuated by a hiring process Hughes [6] shared next to no certified school leader ever received any preparatory training in. How can this lack of foresight, which actually seems to shock people when it sneaks up on them, be any less significant with growing shortages of quality teacher candidates? Just because the term "high quality" is bantered about in statute, does not mean the candidates are necessarily all that is hoped for. Nor does it guarantee, that the best will be selected by a group of 
people who typically have no training in the task they are carrying out. Toss in addressing significant and enduring conflict, enhancing school safety, or taking on competing rights because of special education or medical allergies. Then throw in being dragged into multiple custody battles involving your students on a daily basis, and now picture the demands for immediate advanced leadership being placed on even a novice administrator. Do the trainings, resources and conditions in public schools set these people up for success, or something else?

\section{K-12 Conditions}

We are living in a time when nurturing out-of-thebox thinking is being advocated more frequently by scholars who strive to better develop the organizational capacity to address tomorrow's challenges [11]. In truth, however, an alarming amount of the thought shaping instruction and the operation of American schools today, is far more indicative of a dominated system. In the United States K-12 institutions are visibly being contained by the political structure and dominated by social forces vying for increased control. Hughes has referred to the "captive state" schools and their leaders find themselves in as result of the current climate in the country [5], and cites the added stress this creates, on novice leaders in particular. When public education was originally conceived in the United States, the immediate community was the primary customer, external stake holder and driving force responsible for establishing expectations. Today, the just described modern-day forces targeting schools dominate those original stakeholders as well as the schools serving them.

These additional forces have long included the federal government, state government, as well as state educational agencies. More recently, standards levying professional agencies, assorted think tanks, religious organizations and ultimately even politically aligned cable or internet-based "news" agencies have entered into the mix. This external domination has a welldocumented origin, as every American trained educator knows about the historical events surrounding the launching of Sputnik. The resulting increased emphasis the federal government placed on science and math skills sixty years ago marked the beginning of growing government intrusion into educational content, delivery, and operations. This historic event, has melded with subsequent legislation and countless extended legal challenges, where end results may not be known for years. Together they eventually helped to pave the way to installation of the "compliance model" for public education in America.
Compliance as we know it goes well beyond core topics like math and science. As of late, it can even include the manner in which sporting events are carried out. Every day the list of topics that could further polarize people across the country only expands, and the list often involves education. Sometimes the catalyst for controversy is even an old issue that was long considered resolved, but has recently reemerged. As an example, segregated educational practices that were outlawed in America decades ago, are now resurfacing as legal options in places like Arizona by way of school choice legislation. Classic American judiciary proceedings are falling by the wayside, all while public schools pay a very direct price, as financially driven models like school choice can apparently bypass monumental rulings from federally adjudicated cases [4].

It is becoming clearer and clearer that the locus of control for an organization's decision making continues to be removed even further from local authority. Leaders in public education are often advised to be non-political in their affiliation and conduct, but neutrality is difficult to maintain when schools are continuously being provoked by political ambitions. This is especially so when they are increasingly restricted and financially damaged by politically motivated actions occurring all around them. Whereas the dominated educational system in the United States is a worthy topic of study, it is not the primary topic of this project. Still, introducing it helps strengthen general understanding of yet another set of conditions that presents significant struggle to both the daily and long-term direction K-12 schools and their leaders take.

The next significant concept to be considered has to do with recently changing conditions in graduate level training programs, and how they impact administrator preparedness. The purpose of the section is not to fault higher education, programs, or the people completing them. Rather, the intent is to illustrate many of the changes that have already started to alter the learning conditions for graduate students. As will be introduced in the following section, these developments appear only to strengthen the need for "something else" to be done to help support new administrators.

\section{Higher Education Conditions}

While K-12 education in the United States can trace visible origins of growing domination back to the late 1950s, American higher education largely continued to remain unscathed for years. At a time when the obstacles menacing school administrators have never been greater, the very higher education 
preparatory programs tasked with guiding their development have faced recent challenges that they are not accustomed to [9]. It would be convenient to quickly represent the new challenges as mirroring those experienced in K-12, and leave it at that. Still, it is important to make more specific observation concerning the recent changes. After all, they are affecting the instructional delivery offered by the very programs that exist solely to prepare education's leaders to meet challenges both today and tomorrow.

Unpopular as it may be in the corridors of higher education, accountability that was at one time only talked about intellectually, as a hindrance to be avoided at all cost, has now invaded this proud American institution. Sadly, it appears that the pace is actually only picking up speed. The University of Wisconsin, once considered the bedrock of intellectual freedom in America, was recently fenced in by state government. It experienced significant realignment of its priorities, and abandonment of many time-honored practices in only a matter of months. The net result appears to be one wherein leadership programs must decide between meeting national accreditations standards, or choosing expectations created by governing bodies including state boards of regents.

Either way, higher education must also now please an external master that is very far removed from the day-to-day activities and understandings of faculty members responsible for training tomorrow's educational leaders. Basing decisions and priorities on events taking place in the field is becoming a distant memory at all levels of education in the United States. While for all intents and purposes everything mentioned is certainly legal, it does not mean it is automatically more effective, or necessarily benefitting training for upcoming educational leaders or the communities they serve.

Consider next how a growing number of American educational leadership programs have also fairly recently reduced their overall graduation requirements by at least one or two courses, and perhaps more. In doing what it takes to make programs more marketable, or perhaps appease accreditation boards, many students completing their programs receive less training now than was required at a time when matters were far less complex or dominated. Realistically, it is unlikely that this development will garner much attention, as program completion now comes more swiftly. Still, when administrators increasingly encounter situations where they feel less than adequately prepared, it may become more apparent that trends just described likely have more to do with recruitment and retention of students than completeness of administrator preparation.
The advent of online learning has only fueled this development, as programs are now competing across states, and at times even nationally for many of the same students. Market driven thinking now competes with and likely more accurately dominates decisionmaking that once centered almost completely upon best practice. No one disagrees that many programs are more convenient now. There is also ample effort and literature to argue that the online programs, by design, are as robust as face-to-face instruction. Increasingly there are even standards that affirm all of this. Still, both instructional and student experiences confirm that these more convenient programs are often also lacking much of the integration that traditional face-to-face courses typically had. One argument being offered in defense of new practices often lacking "face time" is that they increasingly utilize adjuncts who are perhaps more current in their fields than some full-time faculty. The impacts of adjuncts will be considered next.

There is no denying there are wonderful adjunct faculty members in leadership programs. More immediately concerning, perhaps, are the economics behind the recently increasing percentage of adjunct faculty as compared to permanent faculty. While it is easy to promote that practical experience are more commonly shared by adjuncts, universities do not ordinarily make the same investment in adjuncts that they make in full-time faculty. Yet they are often becoming the clear majority in the instructional delivery system. Sadly, a higher percentage of parttime faculty not even expected or empowered to be invested in program development, also represents less competition for the compliance oriented priorities that are overrunning higher education. Even assuming that adjuncts are every bit as good as full time faculty instructionally, they do not fulfill program, scholarship or service duties, and thereby leave the institution as a whole less viable than was the case, even a decade ago.

Reduced course requirements, less directly involved faculty roles, and increased commitment to compliance activities have all emerged as potentially negative influences on educational leadership programs. Though there is not a lot of attention being directed toward the aftereffects of these developments, it is difficult to ignore the potential negative impacts these developments could bring. Such a development could ultimately leave K-12 schools in a very visible bind when hiring future leaders who are not as thoroughly prepared as they had once been. Suffice it to say recent developments in higher education, and resulting program changes, contribute to making a case for additional post-graduation resources for novice school administrators. Instead of further exploring the motivations and dynamics behind these changes, the 
focus of this paper next shifts toward investigation of an alternate strategy to combat these concerns.

\section{Research Descriptors}

There is a well-established body of scholarship connected to the topic of educational mentoring, though the focus itself is somewhat scattered. Whether the literature is related to supporting novice teachers or focused on providing resources for novice administrators, there are some givens. First, mentoring itself is in no way a new approach that has recently gained popularity. Nor is there a distinct or popular working definition of mentoring that has been widely accepted or utilized across the literature. Mentoring, in some form or fashion, is believed to have been around since the beginning of recorded history. For the most part, the body of scholarship delves into evidence supporting its general application, or else explores a series of variations or nuances that clearly contribute to the breath of overall understanding.

Along with indicators supporting its general use, there is evidence that mentoring for new administrators has broad immediate value, and potentially offers continued benefit as educational leaders are presented with increasingly complex challenges [11]. The literature often advocates for formal agreements, and promotes definitions and training, though again there is also evidence and experience that suggests none of these are actually necessary. Ranging in perceived value from being a good idea to becoming an actual licensing requirement in states like Washington and Kansas, administrator mentoring efforts appear to be increasing. Methods of carrying out this assistance vary, and one strand of research has even started to focus on electronic mentoring, wherein communication technology is used either to enhance, or perhaps even serve as the backbone for rendering the mentoring itself. E-mentoring already has benefits, even if the scholarly attention to this approach is only starting to emerge. Obviously, as the very title of this paper suggests, it was a prominent feature in and secondary focus of this project.

The focus of this project is primarily aimed at documenting the nature of and benefits from an informal mentoring relationship developed between a recent graduate and current faculty member following completion of a master's program in educational leadership. The interaction and outcomes from this arrangement are viewed in comparison to the general literature, as well as with formal mentoring practices that were concurrently experienced by the novice administrator. The manner through which technology assisted with communication serves as a secondary though noteworthy focus. Finally, this paper is certainly conceptual, but also forwards case study insights derived from the actual working experiences of the novice administrator, who successfully completed her first year in administration in Washington during the course of this project.

\subsection{Data Management}

From a methodological standpoint, it is appropriate to point out here that some of the very barriers that actually inhibited the referenced mentoring efforts, ultimately assisted quite nicely in data collection and management efforts. For the more local interactions, the novice administrator had access to her own calendar, emails, text messages, and notes she took while interacting with her team of mentors. There were also multiple permanent products created and reexamined. As communication with the university mentor was limited by a distance of some 1,000 miles, it was effectively and completely done electronically. With the exception of three Skype sessions to clarify concepts already discussed through other electronic means, and one phone conversation, all communication was carried out either by way of text message or occasional email.

All of the information that pertained to this study was kept and organized for later review and comparison to other artifacts and interactions that took place with formally assigned mentors. Both investigators had access to all of the data, which was useful for augmenting perceptions that had developed as result of extensive interactions which had taken place during the new administrator's first year. As could be expected, with the shift at this point to the case study focus, the voice of this paper will change. This shift is intended to best communicate the rich information obtained through the case study efforts as technical information has largely already been shared.

\section{New Administrator Mentoring}

Mentoring in and of itself, including for new administrators, is not a new concept. However, when considering the increased complexity of challenges faced by today's novice administrators, along with recent adjustments to their preparation, it has never appeared to be more important than it comes across right now. Mentoring demonstrates all of the benefit recommended by experts focusing on improved continuing professional development [14]. It has outstanding potential value if approached within the framework advanced by Pedersen [12], which takes a 
more long-term "investment based" holistic pathway to quality continuing professional development.

For purposes of this project, mentoring is considered to be a relationship that is either formally or informally established. It is a relationship where someone with greater administrative experience and insight than the novice, agrees to support that new administrator for an extended period of time. There is more to mentoring than the descriptor just expressed. However, there are typically differences in the specific operationalized contexts enjoyed in various mentoring relationships. So, we have opted to go with a simpler definition, as it appears to cover a wider array of potentially beneficial relationships, most notably including the one described here. For purposes of further discussion on this topic, we will consider new administrator mentoring from the context experienced by a novice school administrator in the state of Washington. The following information is intended to be descriptive, more so than technical, in order to generate rich insights into the benefits of mentoring rather than focusing on terminology.

The contextual framework guiding this work and essentially all concepts being advanced here represent a best-intended response to escalating challenges faced by new administrators. These include but are not limited to continually revised national standards, the growing set of complex realities faced by new administrators, and the fact that many of them are receiving less coursework in their preparation than was the case for their predecessors. The working construct itself, and criteria found here complement concepts espoused by the Association of Washington School Principals (AWSP) [1], and have not come from any level of government, any national council on education, or any university. The construct is viewed to be well conceived, highly beneficial, and able to be replicated successfully across a variety of professional settings. It was tremendously beneficial for the new administrator who is a partner in this research project.

\section{Formal Mentoring Relationships}

Responding both to the AWSP construct and the personal reality faced by the new administrator, two formal mentoring relationships were initiated by the employing school district. One internal mentoring situation was set up with another elementary principal who works in the same school district. She had been an administrator in the same district for the preceding three years. Another formal mentoring relationship was also created. This one, a bit more unique, was considered to be an "outside" mentoring relationship. It was established with a consultant who worked with leaders across the district, but was also contracted to provide mentoring services to novice administrators. This mentor has over 20 years of experience as an educator, administrator and consultant. Both mentoring relationships were defined, formally, following the AWSP construct already mentioned. They were for the 2015-2016 academic year, which was the novice administrator's first year as an elementary principal for the Oak Harbor School District in Oak Harbor, Washington.

Re-examining a year of formal AWSP sanctioned mentoring provided both expected and somewhat more involved insights. The internal mentor proved highly insightful and was instrumental in developing an understanding of day-to-day expectations for a building principal. The internal mentor was great at introducing the novice administrator to the system. She knew the politics and the practices in the principal's building role and across the district. Just as importantly and at a deeper level, the internal mentor also offered regular encouragement and support. These worthwhile outcomes were consistent with experiences reported in the literature.

Though also a formally articulated relationship, the external mentor represents a less common arrangement than the internal mentor relationship typically takes on. This role and relationship was defined up front, and the early discussion centered on the novice administrator's building and district-level professional goals. The purpose of this relationship, with the outcome proving highly successful as well, was to articulate areas of growth and plan ways to meet those expectations. This relationship was so valuable to the novice, that she formally requested it continue for an additional year to work in greater depth on updating the vision and mission statements for the school. Finally, and really due to the unique qualities of the person filling the external mentoring role, the novice found opportunity to zero in on very specific matters and even personnel challenges taking place in her building. Both formal supports were highly beneficial, though from the very outset having two resources represented a rather unusual configuration.

\section{Informal Supports}

It is highly unlikely that there is any setting or circumstance where credible mentoring of some sort would fail to legitimately benefit a new administrator. In smaller more isolated settings, there could be fewer options to draw from, and potentially even greater need due to limitations on resources. To this point, the focus of this paper has been linked to formally defined mentoring supports, including evidence as to why they 
appear to be increasingly necessary. During the course of this study, despite the fact that there were two formally arranged mentoring relationships, the novice also reported deriving consistent benefits from supportive professional relationships which were not formally established or defined.

There were multiple instances where working relationships quickly presented the potential to become ongoing supports. These supports are seen as being highly valuable for an assortment of reasons. As administration is a lonely undertaking, it comes as no surprise that worthwhile social outlets were welcomed as result of these contacts. Similarly, whether a coworker or administrative contacts in other organizations, insightful experienced encouragement, along with having available an assortment of trusted sounding boards proved valuable. The benefits were so pronounced, in fact, that the novice administrator did not feel as though she could have succeeded in her first year were she to have been without these informal supports.

\section{Post-Graduation Faculty Mentoring}

Despite all the incredible formal and friendly informal resources she was afforded, there was still a lingering question that troubled the new administrator. For her it was how she was going to prevent, or at least minimize, losing sight of who she set out to be when she initially committed to begin her training. During the course of her graduate studies, she had gradually become convinced that she needed to conform and fit in if she wanted to succeed. This frame of mind troubled her greatly, as she could feel herself changing in this regard even prior to leaving the classroom. If it was anything she believed set her apart when she started her training, it was her well defined belief system that was integrated into a very personal style of leadership. In her final class, the culminating course on The Principalship, everyone in her cohort consistently commented on immediately seeing people lose track of who they were as an educational leader, as soon as they left the classroom. Even as she transitioned into her first school year, the novice administrator found herself feeling at risk of losing sight of who she set out to be.

Alarmed by experiencing something she described witnessing herself, she was not ready to give up. She did not want to abandon the leader from within she believed guided her to originally pursue her new role in the first place. Her thoughts took her back to her final course, and the online discussions which were so valuable. She could not return to that setting, but instead contacted her former instructor and referenced a moment where he had offered to help any former student, even long after they had completed his course and their program. That offer was what she referenced when she asked if it would be possible to informally bounce questions and situations off of him as she completed her first year in administration. With nothing more than a friendly commitment expressed on both parts, it was agreed that the mentoring focus for the year would start with staying true to who she had originally set out to be, when she started her program.

With the focus settled, it was necessary to work out communication practicalities. Having 1,000 miles separating them on an everyday basis, it was obvious that electronic communication would be a necessity. Though the emerging literature often comments on the complication and cost inherent in electronic or "ementoring" and views it as an issue that challenges the viability of the approach [8], the solution in this instance was very informal, efficient and highly effective. It was agreed that communication would primarily take place through text messaging. As an option, it was immediate while also nonintrusive, and it was free. When circumstances warranted it, a total of three skype sessions were held, and there was one morning phone call about a special education concern. Emails were used to attach documents, but texting was the norm. While the communication was being settled, it was further agreed that the advice provided would complement the planned formal mentoring instead of competing with it. Outcomes from this mentoring relationship will be considered next, alongside the benefits described from the more formal mentoring efforts.

\section{Benefits All Around}

This section summarizes the benefits realized through the various mentoring relationships described in this paper. As is suggested by the heading in this subsection, benefits were derived in an ongoing manner both by the novice administrator as well as by the mentor on behalf of the university. In as much as the purpose of mentoring was to benefit the recent graduate, and in as much as there is far more context with which to reflect on the relationship in the K-12 arena, there will be greater focus and discussion on benefits to the novice. When it comes to mentor, and ultimately essentially university benefits, these are relatively unique outcomes that will be addressed upfront. Combined, the results reported here represent an effective alternate pathway for identifying and meeting novice administrator needs that differs from more common priorities and approaches that were described earlier in this paper. 
The return on investment for both parties was immediate and significant. The beauty of the relationship for the university is that the mentoring described here immediately helped support the new administrator, and the insights being exchanged between mentor and mentee also immediately benefitted current and future graduate students as well. That is because in "real time" the faculty member received at least weekly, and at times daily knowledge of the major issues the new administrator needed help with. There was, then, the opportunity to help her, immediately, and also quickly refine delivery of instruction in a course he teaches three times a year.

There were two key areas of focus that stood out all year long and deserve mention as result. These areas of particularly strong challenge for the new administrator had to do with conflict resolution and complications associated with special education issues. That the administrator needed more assistance with conflict resolution and special education dealings really actually came as no surprise. It was believed by the mentor even while teaching The Principalship course that students would be lacking sufficient exposure to these areas. Though there actually were discussions, activities, presentations and resources provided in the class for these topics, experience and inputs from the field only further strengthened the instructor's resolve to place increased emphasis on these concepts.

From the practitioner side, which was the primary focus of the mentoring relationship, several expected and perhaps even a couple unexpected developments stood out. First and foremost, it need be noted that all of the supportive efforts described within this paper were valued and found to be extremely beneficial by the new administrator. The formal internal mentor provided orientation, a valued sounding board, and advocacy for the new administrator right from the start. The formal external mentor, as mentioned, was in sync not only with planning and goal setting efforts, but also proved to be a personal resource, who was also found to be a strong advocate for the new administrator. Truly these resources, along with colleagues, friends, and family members were all vital contributors to first year success.

The university oriented mentoring was just one piece of the support system for the administrator in this vignette. However, it is perhaps the least common, and likely the most individualized or most "personal." This was due to the fact that she was looking for someone to help guide her overall thinking, and to process challenges along with inputs from others, including her other mentors. Once the year had started, she voiced more than once how she was reliving her graduate training on a daily basis. However, in this case, she was able to walk through "live" next steps with her professor-mentor.

Special education issues, and conflict were repeated topics being discussed regularly. Understanding some of the hidden complexities of human resources situations also helped the mentee to better appreciate why certain select sensitive matters were not addressed as openly as she might have expected. She practiced preparing for "hard conversations" that she really did at times with either formal mentor, but felt safest pursuing in this relationship. And, as was her intent from the very beginning, this mentoring relationship was the one where she got to build on who she set out to be, and felt safe in questioning how all of that effort to "do it her way" was turning out.

The perspective she was afforded was necessary, as in her words, it is particularly isolating to lead an elementary building where there are no assistants at an administrative level to integrate into a team. In this more isolated world, as she pointed out more than once, case studies from classes were not enough to draw on. It was so much better to be able to bounce her thoughts off a trusted advisor who had experience, expertise, understood her, and as it happened demonstrated an approach to leadership that was very much in sync with who she had always set out to be.

As she said herself, sometimes it felt like she was going through her Principalship class all over again. Having similar discussions to those that took place in class were both timely and very refreshing for her. Now, of course, the issues were real, they were hers, and they were far more complicated than the scenarios that were originally discussed with classmates. This "just in time" style of mentoring provided her an opportunity to continue to grow by learning how to think, how to focus, and how to approach issues now and down the road. It was no more significant to success in her first year than any of the other training or resources. It was, however, a bit more customized and as mentioned, and helped her to integrate other lessons from other interactions as much as it was a focus of its own.

\section{Conclusion}

This project resulted from an unplanned, informal and highly customized mentoring arrangement that has just been described. It represents a cooperative "extended" effort established to help initially address remaining immediate needs for a newly trained and hired principal. It bears repeating that the novice administrator was a highly-regarded educator and graduate. She had valuable "onsite" support through formal resources and informal interactions. The 
perceived need to initiate the university mentoring relationship in no way diminishes the value of these resources. Rather, this story has at least as much to do with the educator's desire to stay true to who she originally set out to be as a leader. She recognized a "drift" away from her core leadership dispositions as she was completing her training, sought support to bring her back in line with original beliefs, and additionally sought to address perceived gaps in her formal graduate program training.

There were multiple factors that contributed to the just mentioned "drift." Looking ahead to complex and stressful daily demands, and becoming more aware of an increasingly dominated educational climate all lead the future leader to question whether she had to change who she was, just to compete for a job. Then she recalled conversations with classmates, where it was agreed that no one wants genuine, credible leadership more than the teaching staff. Where the group commented that they consistently saw a change away from this desired leadership, while watching most new administrators transition into their role. In short time, she realized she would be far more successful staying true to her leadership beliefs and practices. It was at that point she solicited the added assistance she thought she needed to help her succeed as the type of credible leader fellow educators were clearly looking for.

In many ways, the relationship described here likely returns us to an earlier time when face-to-face interactions, ahead of online learning, allowed for much more direct communication between parties. There was also once considerably more investment and guidance from faculty member to student as full-time faculty were then more the norm. The resulting distance from "distance learning" that is taking place today, contributes to making the relationship just describe unique in today's educational arena. In any case, it was viewed to be a "win-win" undertaking as the "just in time" communication benefitted both parties.

At this point, focused insights are being offered as opposed to listing specific recommendations. As another graduate student [10] reminded the authors, not every professor would have the background or inclination to render this assistance. Nor would every leader be open to all of the feedback this recent graduate worked with. On top of this, it is not practical to expect what took place here to become the latest "standard" written into some accountability piece for K-12 or higher education. Therefore, focused "insights" are offered as opposed to "recommendations."

Clearly, mentoring is valuable. That conclusion was established long before this project even began.
Mentoring and related supports can be valuable when they are formally defined, and even if they are more informally conceived. The findings from this project confirm that, and suggest there are instances when having multiple mentors along with informal supports could be of tremendous value.

The focus of mentoring could support a variety, and combination of needs. Acclimation, or learning the ropes, are the most widely understood and talked about examples. Augmenting skills and developing insights concerning complex challenges that may not have been sufficiently mastered in graduate school are additional possible outcomes realized through this project. Having a coach, advocate, or champion to help a novice stay true to their values and original intentions is another consideration, and was an original concept that motivated this undertaking. Helping to model and reinforce "thinking out-of-the-box" as a means of problem solving is yet another desirable outcome that was realized through this project.

Every mentoring relationship is different. In this instance, the mentor is a former superintendent, who has human resources, special education, as well as extensive legal background, having served also as a director of special education and a school psychologist. He pretty much had the makeup the mentee was looking for to support her continued growth. Rather than recommending new expectations based on this one experience, the story is meant to show what is at least possible, and certainly acknowledge that a "good fit" is certainly a significant ingredient for success.

Assuming distance education continues to take over higher education programs, and as training struggles to keep up with demands, university provided mentoring could prove to be even more valuable in the future. The best person to serve as mentor might be found in the full-time faculty, or perhaps among the ranks of adjuncts practicing in the field. But results support that notion that continued collaboration with a faculty member was highly beneficial. It was an experience that seemed worthy of sharing as it worked so well, even up to and including the "no cost" texting option for communication. Not intended to be represented as a blanket solution, rather it is an option that a new administrator sought out, feels she benefitted from tremendously, and wanted to share with others.

\section{References}

[1] Association of Washington School Principals, (2016). Mentoring framework. http://www.awsp.org/resources/ Framework Criteria. (Access Date: 15 September, 2016) 
[2] Augustine-Shaw, D., and Liang, J., (2016). Embracing new realities: Professional growth for new principals and mentors. Educational Considerations. 43(3), 10-17.

[3] Bryson, J., (2011). Strategic planning for public and nonprofit organizations (4 ${ }^{\text {th }}$ Edition), Jossey-Bass, San Francisco.

[4] Hockheim, R., Marin, M., Packard, D., and Hughes, T. (2016). Legalized segregation of education: In Arizona it's called privatization. Paper presented at 2016 Arizona Professors of Educational Administration Annual Conference, Phoenix AZ.

[5] Hughes, T., (2014). Leadership under captivity: Coping with the legal and political landscape in Arizona education. Presentation at 2014 Annual Arizona Council of Occupational/Vocational Administrators (ACOVA) Fall Conference, Prescott, AZ.

[6] Hughes, T., (2014). Hiring at risk: Time to ensure hiring really is the most important thing we do. International Journal of Educational Leadership Preparation, NCPEA Press, 8 (1), 90-102.

[7] Kahane, A., (2012). Transformative scenario planning, Berrett-Kohler Publishers, San Francisco.

[8] Kahraman, M., and Kuzu, A. (2016). E-mentoring for professional development of pre-service teachers: A case study. Turkish online journal of distance education, ISNN 1302-6488 17(3) Article 6, 76-89.

[9] Mouw, J. and Hughes, T., (2016). Extended university mentoring: Supporting early administrator success while realizing important training insights, National Council of Professors of Educational Administration (NCPEA) 2016 Annual Conference, Detroit.

[10] Morrison, R., (2016). Personal conversation.

[11] Owen, L., Guilott, M., and Parker, G., (2016). Using Powerful Tools for Instructional Leadership, International Journal for Cross-Disciplinary Subjects in Education, Infonomics Society, 2807-2816.

[12] Petersen, K., (2002). The professional development of principals: Innovations and opportunities, Educational Administration Quarterly, Sage Publications, 213-232.

[13] Pitmann, A. (2014) An Examination of the impact of mentoring on new administrators, ProQuest LLC, UMI Number: 3613820.

[14] Zimmerman, J., (2002). Providing effective professional development: What's holding us back, American Secondary Education, 31(2), 37-48. 